\title{
ENRAIZAMENTO DE ESTACAS DE BOUGAINVILLEA COM CONCENTRAÇÕES DE ÁCIDO NAFTALENOACÉTICO
}

\section{ROOTING OF BOUGAINVILLEA CUTTINGS WITH CONCENTRATIONS OF NAPHTHALENE ACETIC ACID}

\author{
Amanda Pacheco Cardoso MOURA ${ }^{1}$ \\ Vanessa Padilha SALLA ${ }^{1}$ \\ Daniela Macedo de LIMA ${ }^{2}$
}

\begin{abstract}
RESUMO
O presente trabalho teve como objetivo avaliar o enraizamento de estacas de primavera (Bougainvillea spectabillis Willd.) com aplicação de ácido naftalenoacético em diferentes concentrações. O experimento foi realizado no Viveiro Florestal da Universidade Tecnológica Federal do Paraná Campus Dois Vizinhos, sendo coletados ramos semi-lenhosos para a confeção de estacas de $10 \mathrm{~cm}$, com um par de folhas com a superfície reduzida à metade. $O$ delineamento experimental foi inteiramente casualizado com quatro tratamentos e quatro repetições de 16 estacas por parcela. $O$ experimento foi composto pelos tratamentos: T1 (testemunha), T2 (1000 mg L-1 ANA), T3 (2000 mg L-1 ANA), T4 (3000 mg L-1 ANA). Aos 90 dias avaliou-se as porcentagens de estacas enraizadas, com calos, vivas, mortas, com brotações, número médio de brotações por estaca, número e comprimento médio de raízes formadas por estaca $(\mathrm{cm})$. De modo geral as porcentagens de enraizamento da espécie foram baixas, sendo o tratamento $4(40,63 \%)$ significativamente maior que a testemunha $(1,56 \%)$. Quanto ao número de raízes formadas por estaca, verificou-se maior média para o tratamento $4(10,75)$, diferindo estatisticamente da testemunha $(1,50)$. Para o comprimento médio de raízes, o tratamento $2(8,94 \mathrm{~cm})$ diferiu significativamente da testemunha $(2,38 \mathrm{~cm})$. A mortalidade de estacas foi elevada, sendo superior para a testemunha $(70,31 \%)$. Nas condições de realização do presente trabalho, conclui-se que a concentração $3000 \mathrm{mg} \mathrm{L}^{-1}$ é a mais adequada para a promoção do enraizamento da espécie.

Palavras-chave: auxina; estaquia, propagação vegetativa; Bougainvillea spectabillis.
\end{abstract}

\begin{abstract}
This study aimed to evaluate the rooting of Bougainvillea spectabillis Willd. with application of naphthalene acetic acid at different concentrations. The experiment was conducted in Forestry Nursery of the Universidade Tecnológica Federal do Paraná Campus Dois Vizinhos. Semi-hardwood branches were collected for cuttings confection of $10 \mathrm{~cm}$. The experimental design was completely randomized with four treatments and four replications of 16 cuttings per plot. The experiment consisted of the treatments: T1 (control), T2 (1000 mg L-1 NAA), T3 (2000 mg L-1 NAA), T4 (3000 mg L-1 NAA). After 90 days we evaluated the percentages of rooting, of cuttings with callus, alive, dead, with shoots, average number of shoots per cutting, average number and average length of roots per cutting $(\mathrm{cm})$. Generally, the root percentages were low, and the treatment $4(40.63 \%)$ was significantly higher than the control $(1.56 \%)$. Regarding the number of roots per cutting, there was a higher mean for treatment $4(10.75)$, differing from the control (1.50). For the average length of roots, the treatment $2(8.94 \mathrm{~cm})$ differed significantly from the control treatment $(2.38 \mathrm{~cm})$. The cuttings necrosis was higher than the control $(70.31 \%)$. Under the conditions of accomplishment of this work, its concluded that the concentration $3000 \mathrm{mg} \mathrm{L}^{-1}$ ANA is the most appropriate for promoting rooting of the species.
\end{abstract}

Key words: auxin; cutting, vegetative propagation; Bougainvillea spectabillis.

\footnotetext{
${ }^{1}$ Acadêmicas do curso de Engenharia Florestal, Universidade Tecnológica Federal do Paraná, Campus Dois Vizinhos (UTFPR-DV). Bolsista da FUNDAÇÃO ARAUCÁRIA/UTFPR-Brasil.

${ }^{2}$ Bióloga, Doutora, Professora, UTFPR-DV, Estrada para Boa Esperança, km 04, Comunidade São Cristóvão, CEP 85660-000, Dois Vizinhos, Paraná, Brasil. danielamlima@ufpr.edu.br.
} 
MOURA, M.P.C. et al. Enraizamento de estacas...

\section{INTRODUÇÃO}

A espécie Bougainvillea spectabillis, Willd. também conhecida como três-marias, primavera e buganvília, pertence à família Nyctaginaceae É um arbusto lenhoso e com espinhos, nativo do Leste e Nordeste do território Brasileiro, muito utilizado pelo seu potencial ornamental, podendo atingir até 12 metros de altura, tendo ramos fortemente armados variando de 2,5 a 5 centimetros (Marchiori, 1997; Stumpf, 2010).

A família Nyctaginaceae possui espécies com porte em sua maioria de ervas, arbustos, árvores ou lianas. Suas folhas são alternas ou opostas, simples e sem estípulas com inflorescência bissexuadas ou unissexuadas, actinomorfas e monoclamídeas. Sua distribuição é pantropical, possuindo cerca de 30 gêneros e 400 espécies, onde no Brasil ocorrem cerca de 10 gêneros e 70 espécies. Alguns outros exemplos de espécies desta família são: Andradea floribunda Allemão, Neea theifera Orsted e Guapira opposita (Vell.) Reitz (Lorenzi \& Souza, 2008).

O florescimento desta espécie ocorre no outono e na primavera e suas flores são envolvidas por três brácteas bem vistosas, simples ou dobradas de diversas cores, entre elas vinho, laranja, branco e rosa. Pode ser cultivada a pleno sol como trepadeira para revestir cercas, porém, esta espécie não é tolerante a geadas fortes (Lorenzi \& Souza, 2008). A propagação da espécie é comumente realizada através da propagação vegetativa, tanto por meio da técnica de estaquia como por alporquia (Lorenzi \& Souza, 2008; Stumpf, 2010).

De acordo com Hartmann et al. (2002) a propagação vegetativa apresenta inúmeras vantagens quando comparada a propagação por meio de sementes. Isso se deve ao fato da técnica ser considerada de baixo custo, simples e rápida, podendo produzir um grande número de mudas em um curto espaço de tempo, ao passo que as mudas apresentam-se uniformes e com as mesmas características da planta matriz, reduzindo também o período de juvenilidade das mudas produzidas. Todavia há desvantagens em relação a este método, o que segundo Ferrari et al. (2004), deve-se à obtenção de brotos que sejam viáveis, ou seja, com boa capacidade de enraizamento e posterior adaptação a campo.

Uma das variáveis mais importantes no que diz respeito à propagação vegetativa é o enraizamento. São muitos os fatores que influenciam a formação de raízes em estacas: condições fisiológicas e idade da planta matriz, tipo de estaca, época do ano, capacidade genética de enraizamento, quantidade de hormônios endógenos, oxidação de compostos fenólicos entre tantos outros (Fachinello et al., 2005).

Para algumas espécies que apresentam dificuldade de enraizamento ou então para um meIhor resultado na produção de mudas é comum o emprego de reguladores vegetais como as auxinas sintéticas, dentre as quais podemos citar o ácido indolbutírico (AIB) e o ácido naftaleno acético (ANA)
(Norberto et al., 2001). Essas auxinas podem ser aplicadas na forma líquida, por embebição das bases da estacas em soluções aquosas ou até mesmo em soluções alcoólicas (Hartmann et al., 2002). O tempo de imersão vai depender da concentração de auxinas e do tempo de imersão nas soluções utilizadas. Estacas tratadas com soluções diluídas $(0 \mathrm{a}$ $500 \mathrm{mg} \mathrm{L}^{-1}$ ) necessitam ter suas bases imersas durante, já para concentrações mais elevadas acima de $500 \mathrm{mg} \mathrm{L}^{-1} \mathrm{o}$ contato das bases das estacas é de apenas alguns segundos (Couvillon, 1988).

Esse trabalho teve por objetivo avaliar o enraizamento de estacas de Bougainvillea spectabillis com aplicação de ácido naftalenoacético em diferentes concentrações.

\section{MATERIAL E MÉTODOS}

O experimento foi conduzido no Viveiro Florestal da Universidade Tecnológica Federal do Paraná, Câmpus Dois Vizinhos, no período de dezembro de 2010 a fevereiro de 2011. Ramos semilenhosos foram coletados de uma planta matriz pertencente ao Viveiro do Câmpus, dos quais foram confeccionadas estacas de $10 \mathrm{~cm}$ de comprimento, com corte em bisel na base e corte reto acima da última gema axilar, mantendo-se um par de folhas com a superfície reduzida à metade. Estas foram submetidas a tratamento fitossanitário em solução de hipoclorito de sódio durante 15 minutos e logo após foram enxaguadas em água corrente. As estacas tiveram suas bases imersas em solução aquosa de ANA nas concentrações 0,1000, 2000 e 3000 $\mathrm{mg} \mathrm{L}^{-1}$, durante 10 segundos. O plantio foi realizado em tubetes contendo substrato vermiculita de granulometria fina. As estacas foram mantidas em casa -de-vegetação com três irrigações diárias de 15 minutos.

O delineamento experimental utilizado foi inteiramente casualizado, com 4 tratamentos e 4 repetições de 16 estacas por parcela. Aos 90 dias após o plantio, foram avaliadas as variáveis: porcentagem de estacas enraizadas, vivas não enraizadas, com calos, com brotações e mortas, número médio de brotações por estaca, número e comprimento médio de raízes formadas por estaca $(\mathrm{cm})$. Os dados foram submetidos à análise de homogeneidade de variância pelo teste de Bartlett e análise de variância $(P \leq 0,05)$, utilizando o programa MSTAT-C ${ }^{\circledR}$, versão 2.10

\section{RESULTADOS E DISCUSSÃO}

Para a porcentagem de estacas enraizadas de $B$. spectabillis verificou-se baixos índices de enraizamento (Tabela 1). Por meio da análise estatística verificou-se diferença significativa entre os tratamentos testados, sendo que a concentração 3000 $\mathrm{mg} \mathrm{L}^{-1}$ obteve maior porcentagem de enraizamento $(40,63 \%)$ quando comparado à testemunha $(1,56 \%)$, sendo possível perceber a influência da auxina nesta variável.

Resultados semelhantes foram encontrados por Endres et al. (2007), cujas estacas de Ca- 
esalpinia echinata Lam tratadas com $5000 \mathrm{mg} \mathrm{L}^{-1} \mathrm{de}$ ANA obtiveram maior índice de enraizamento $(16 \%)$ em relação às estacas tratadas com $2.500 \mathrm{mg} \mathrm{L}^{-1}$, com cerca de $8 \%$ de enraizamento. Em estacas de Laurus nobilis L. com quatro folhas, a adição de $2000 \mathrm{mg} \mathrm{L}^{-1}$ de ácido indol butírico proporcionou o maior índice de enraizamento, cerca de $50 \%$, supe- rior à testemunha (25\%) e a concentração $1000 \mathrm{mg}$ $\mathrm{L}^{-1}$ que apresentou aproximadamente $40 \%$ (Fochesato et al., 2006). Já Colodi et al. (2008) em estudos com Mikania glomerata Spr. não obteve diferenças estatísticas na porcentagem de estacas enraizadas com a utilização de ANA nas concentrações utilizadas (2500 $\mathrm{mg} \mathrm{L}^{-1}$ e $\left.5000 \mathrm{mg} \mathrm{L}^{-1}\right)$.

TABELA 1 - Porcentagem de estacas enraizadas, número e comprimento médio de raízes formadas por estaca, de B. spectabillis. UTFPR, Dois Vizinhos - PR, 2011.

\begin{tabular}{|l|c|c|c|}
\hline \multicolumn{1}{|c|}{ Concentração ANA (mg L } & ER & NRE & CRE (cm) \\
\hline 0 & $1,56 \mathrm{~b}$ & $1,50 \mathrm{~b}$ & $2,38 \mathrm{~b}$ \\
\hline 1000 & $23,44 \mathrm{ab}$ & $6,34 \mathrm{ab}$ & $8.94 \mathrm{a}$ \\
\hline 2000 & $35,94 \mathrm{ab}$ & $4,43 \mathrm{ab}$ & $8,00 \mathrm{ab}$ \\
\hline 3000 & $40,63 \mathrm{a}$ & $10,75 \mathrm{a}$ & $7,79 \mathrm{ab}$ \\
\hline Média & 25,39 & 5,75 & 6,77 \\
\hline Teste de Bartlett $\left(\mathrm{X}^{2}\right)$ & 6,92 & 4,46 & 8,160 \\
\hline CV $(\%)$ & 67,13 & 66,60 & 41,02 \\
\hline
\end{tabular}

Médias seguidas da mesma letra não diferem significativamente pelo teste de Tukey a $5 \%$ de probabilidade.

$\mathrm{EE}=$ estacas enraizadas; NRE = número médio de raízes por estaca; CRE = comprimento médio de raízes por estaca; C.V.= coeficiente de variação.

Embora tenham sido verificados baixos índices de enraizamento no presente trabalho, esses resultados podem ser atribuídos à espécie em questão. Carvalho et al. (2002) obtiveram altos índices de enraizamento com a espécie azaléia em todos os tratamentos com ANA, obtendo uma média final de $81,60 \%$ de estacas enraizadas.

A auxina pode ser utilizada no enraizamento de muitas espécies, alem de proporcionar um maior índice de enraizamento, aumenta formação a velocidade e a uniformidade do sistema radicular (Hartmann et al., 2002). Para Diaz-Sala et al. (1996) o aumento no enraizamento pode variar de acordo com a forma, concentração e método de aplicação da auxina, sendo o que o tipo de estaca utilizado também pode influenciar, bem como a estação do ano em que foi realizada a coleta do material. Já as concentrações elevadas de auxina podem inibir o desenvolvimento de brotações, no entanto, quando as auxinas forem utilizadas abaixo do nível critico, não ocorre formação de raízes adventícias (Hartmann et al., 2002).

As auxinas possuem a finalidade de aumentar a percentagem de estacas que formam raízes, aumentam também o número e qualidade das mesmas, bem como aceleraram a iniciação das raízes. Porém há uma concentração máxima que irá provocar este estímulo, variando por espécie e concentração de auxina já existente no tecido da planta, onde a partir do aumento desta dosagem esta irá promover o efeito inibitório (Fachinello et al., 2005).

Quanto ao número médio de raízes por estaca observou-se que o ANA na concentração
$3000 \mathrm{mg} \mathrm{L}^{-1}$ apresentou o melhor resultado $(10,75)$, diferindo significativamente da testemunha $(1,50)$ (Tabela 1). Esses resultados foram confirmados por Colodi et al. (2008) em experimentos de estaquia de guaco, cuja aplicação de auxinas nas concentrações $2500 \mathrm{mg} \mathrm{L}^{-1}$ e $5000 \mathrm{mg} \mathrm{L}^{-1}$ promoveram a formação de um maior número de raízes, ambas com 40,8 raízes. Tofanelli et al. (2002) também verificaram a formação de maior número de raízes em estacas de pessegueiro tratadas com ANA na concentração $3000 \mathrm{mg} \mathrm{L}^{-1}$. Já Lima et al. (2006) em estudos com diferentes espécies do gênero Calliandra e concentrações de ANA, relataram que para a espécie $C$. selloi não houve diferença estatística para a variável número de raízes, demonstrando que a auxina não possui efeito nesta variável para a espécie estudada.

Quanto à variável comprimento médio de raízes por estaca, o tratamento $1000 \mathrm{mg} \mathrm{L}^{-1}(8,94$ $\mathrm{cm})$ diferiu significativamente da testemunha $(2,38$ $\mathrm{cm}$ ) (Tabela 1). Esses resultados divergem dos obtidos por Cézar et al. (2009) com a espécie Tibouchina fothergilla e Ferriani et al. (2007) com a espécie Mikania micrantha, ambos utilizando ANA, nos quais não houve diferença estatística entre os tratamentos utilizados. Sendo assim, é possível deduzir que o efeito das auxinas é diferenciado em cada espécie, uma vez que o enraizamento pode ser afetado por diversos fatores, dentre eles a idade da planta matriz, estação do ano da coleta do material, genótipo da planta e a utilização de reguladores vegetais, e as condições ambientais como temperatura, substato, luminosidade e umidade (Hartmann 
MOURA, M.P.C. et al. Enraizamento de estacas...

et al., 2002).

Para a variável porcentagem de estacas vivas não houve diferença estatística entre os tratamentos utilizados (Tabela 2). Esses dados corroboram com Lima et al. (2008) que em estudos com estacas caulinares de Maytenus ilicifolia empregando o ácido naftaleno acético, verificaram que a sobrevivência das estacas não foi influenciada pelos tratamentos.

Já para a porcentagem de estacas mortas, verificou-se diferença estatística entre os tratamentos empregados, tendo a testemunha apresentado a maior mortalidade $(70,31 \%)$, quando comparada aos tratamentos $2000 \mathrm{mg} \mathrm{L}^{-1}$ e $3000 \mathrm{mg} \mathrm{L}^{-1}$, com $31,25 \%$ e $28,13 \%$, respectivamente (Tabela 2 ). Este resultado demonstrou que o emprego de concentra- ções mais elevadas de ANA influenciou positivamente na propagação da espécie propiciando aumento na porcentagem de enraizamento e redução na mortalidade das estacas. Dados contrários foram obtidos por Alcântara et al. (2010) em estudo com jambolão, no qual as menores dosagens de ANA proporcionaram menores porcentagens de estacas mortas. Dependendo da dosagem utilizada para os tratamentos é possível haver respostas negativas quanto à aplicação exógena de reguladores vegetais, devido à concentração endógena de auxinas a aplicação exógena de reguladores vegetais poderá causar uma alteração no balanço hormonal, o qual poderá ser desfavorável à espécie (Ramos et al., 2008).

TABELA 2 - Porcentagem de estacas vivas, porcentagem de estacas mortas, porcentagem de estacas com brotações e número médio de brotações por estaca de Bouganvillea spectabillis. UTFPR, Dois Vizinhos - PR, 2011.

\begin{tabular}{|c|c|c|c|c|}
\hline Concentração ANA (mg L L) & EV (\%) & EM (\%) & EB (\%) & NBE \\
\hline 0 & $28,13 \mathrm{a}$ & $70,31 \mathrm{a}$ & $29,58 \mathrm{~b}$ & $2,20 \mathrm{a}$ \\
\hline 1000 & $34,38 \mathrm{a}$ & $42,19 a b$ & $50,00 a b$ & $2,45 a$ \\
\hline 2000 & $38,25 \mathrm{a}$ & $31,25 b$ & $68,75 a$ & $2,78 \mathrm{a}$ \\
\hline 3000 & $23,44 a$ & $28,13 \mathrm{~b}$ & $62,50 a b$ & $2,45 a$ \\
\hline Média & 29,30 & 42,97 & 52,73 & 2,47 \\
\hline Teste de Bartlett $\left(x^{2}\right)$ & 0,661 & 1,888 & 0,834 & 3,533 \\
\hline $\mathrm{CV}(\%)$ & 45,57 & 39,50 & 34,68 & 13,63 \\
\hline
\end{tabular}

Médias seguidas da mesma letra não diferem significativamente pelo teste de Tukey a $5 \%$ de probabilidade. $\mathrm{EV}=$ estacas vivas; $\mathrm{EM}$ = estacas mortas; $\mathrm{EB}$ = estacas com brotações; $\mathrm{NBE}$ = número médio de brotações por estaca; C.V.= coeficiente de variação.

Para a porcentagem de estacas com brotações de $B$. spectabillis verificou-se que houve diferença significativa entre os tratamentos $2000 \mathrm{mg} \mathrm{L}^{-1}$ ANA $(68,75 \%)$ e a testemunha $(29,58 \%)$. No entanto, os resultados obtidos no presente trabalho divergem dos obtidos por Colodi et al. (2008) que não verificou diferença estatística entre as concentrações de ANA testadas para o número de brotações formadas em estacas de guaco, mas foi verificada uma tendência de maior formação de brotações na ausência da aplicação de auxina. Villa et al. (2003) também verificaram que a ausência de aplicação de auxinas em estacas do porta-enxerto de videira 'Riparia de Traviú' proporcionou melhores resultados na indução de brotações, chegando a 73,66\% de estacas brotadas.

Quanto ao número médio de brotações por estaca não houve diferença significativa entre os tratamentos, demonstrando que não houve influência das concentrações de ANA testadas para a es- pécie (Tabela 2). Já em estudo realizado com a aplicação de ácido naftaleno acético em estacas de videira (Riparia de Traviú), Villa et al. (2003) relataram que houve maior formação de brotos na ausência dessa auxina $(10,54)$, diferindo significativamente dos demais tratamentos.

\section{CONCLUSÃO}

Nas condições em que o presente trabalho foi realizado verificou-se que as concentrações de ANA testadas estimularam a formação de raízes, sendo a concentração de $3000 \mathrm{mg} \mathrm{L}^{-1}$ a mais adequada para a promoção do enraizamento da espécie.

\section{AGRADECIMENTOS}

O presente trabalho foi realizado com $O$ apoio da Universidade Tecnológica Federal do Paraná - UTFPR - Brasil. 


\section{REFERÊNCIAS}

1. ALCANTARA, G. B. et al. Efeito dos ácidos naftaleno acético e indolilbutírico no enraizamento de estacas de Jambolão [Syzygium cumini (I.) Skeels]. Revista Brasileira de Plantas Medicinais, v. 12, n.3, p.317-321, 2010.

2.CARVALHO, D. B. de.; SILVA, L. M.; ZUFFELLATO-RIBAS, K. C. Indução de raízes em estacas semilenhosas de Azaléia através da aplicação de ácido naftaleno-acético em solução. Scientia Agraria, v.3, n.1-2, p.97-101, 2002.

3.CEZAR, T. M. et al. Estaquia e alporquia de Tibouchina fothergillae (D.C.) Cogn. (Melastomataceae) com a aplicação de ácido naftaleno acético. Scientia Agraria, v.10, n.6, p.463-468, 2009.

4.COLODI, F. G; RAMOS, N. L. C.; ZUFFELLATO-RIBAS, K. C. et al.; Propagação vegetativa de guaco com adição de ácido naftalenoácetico. Scientia Agraria, v.9, n.1, p.95-98, 2008.

5. COUVILLON, G.A. Rooting responses to different treatments. Acta Horticulture, n.227, p.187-196, 1988.

6. DIAZ-SALA, C. et al. Maturation related loss in rooting competence by loblolly pine stem cuttings: The role of auxin transport, metabolism and tissue sensitivity. Physiologia Plantarum, v. 97, n. 3, p. 481- 490, 1996.

7.ENDRES, L. et al. Enraizamento de estacas de Pau-Brasil (Caesalpinia echinata Lam.) tratadas com ácido indol butírico e ácido naftaleno acético. Ciência Rural, v.37, n.3, p.886-889, 2007.

8.FACHINELLO, J. C.; HOFFMANN, A.; NACHTIGAL J. C. Propagação de Plantas Frutíferas. Brasília: Embrapa Informação Tecnológica, 2005. $221 \mathrm{p}$.

9.FERRARI, M. P.; GROSSI, F.; WENDLING, I. Propagação vegetativa de espécies florestais. Colombo: Embrapa Florestas. 2004. (Documentos n. 94).

10.FERRIANI, A.P. et al. Influência da época do ano e das diferentes formas de aplicação de ácido naftaleno acético (ANA) no enraizamento de Mikania micrantha Kunt. Revista Brasileira de Plantas Medicinais, v.9, n.2, p.102-107, 2007.

11.FOCHESATO, M. L. et al. Propagação de louro (Laurus nobilis L.) por estacas semilenhosas com diferentes quantidades de folhas e tratadas com ácido indolbutírico. Revista Brasileira de Plantas Medicinais, v.8, n.3, p.72-77, 2006.

12.HARTMANN, H.T. et al. Plant Propagation: principles and practices. New Jersey: Prentice Hall. 2002. 880p.

13.LIMA, D. M. de et al.. Substratos e concentrações de ácido naftaleno acético no enraizamento de estacas semilenhosas de Calliandra selloi e Calliandra tweediei. Scientia Agraria, v.7, n.1-2, p.105-111, 2006.

14.LIMA, D. M. de. et al. Substratos e auxinas no enraizamento de estacas caulinares de espinheira-santa. Scientia Agraria v.9, n.1, p.85-89, 2008. (Nota Científica).

15.LORENZI, H.; SOUZA H. M. de. Plantas ornamentais no Brasil: arbustivas, herbáceas e trepadeiras. 4. ed. Nova Odessa Instituto Plantarum, 2008. 1088p.

16.LORENZI, H.; SOUZA, V. C. Botânica Sistemática: guia ilustrado para identificação das famílias de Fanerógamas nativas e exóticas no Brasil, baseado em APG II. 2 edição. Nova Odessa: Instituto Plantarum, 2008. 703p.

17.MARCHIORI, J. N. C. Dendrologia das Angiospermas: das magnoliáceas as flacurtiáceas. Santa Maria: UFSM, 1997. 271 p.

18.NORBERTO, P. M.; CHALFUN, N. N. J.; PASQUAL, M. et al. Efeito da época de estaquia e do AIB no enraizamento de estacas de Figueira (Ficus carica L.). Ciência e Agrotecnologia, v.25, n.3, p.533-541, 2001.

19.RAMOS, D. P.; LEONEL, S.; DAMATTO JUNIOR, E. R. Avaliação da época de estaquia e uso de bioregulador no enraizamento de estacas de figueira. Revista Brasileira de Fruticultura, v.30, n.3, p.748-753, 2008.

20. STUMPF, M. A primavera ou Bouganvillea. Disponível em: http://www.fazfacil.com.br/jardim/trepadeira_primavera.html> Acesso em: 07 nov. 2010.

22. TOFANELLI, M. B. D. et al. Efeito do ácido indolbutírico no enraizamento de estacas de ramos semilenhosos de pessegueiro. Pesquisa Agropecuária Brasileira, v. 37, n.7, p. 939-944, 2002.

23. VILLA et al. Enraizamento de estacas herbáceas do porta-enxerto de videira 'Riparia de Traviú' tratadas com auxinas. Ciência e Agrotecnologia, v.27, n.6, p.1426-1431, 2003. 